\title{
OBITUARIO
}

\section{TESTIMONIO DE JUAN CARLOS \\ GARAVAGLIA (1944-2017): \\ SUS CONTRIBUCIONES A LA HISTORIA \\ ECONÓMICA Y SOCIAL DEL MÉXICO \\ COLONIAL}

Carlos Marichal

El Colegio de México

R ecuerdo que fue en 1980 cuando irrumpió en la vida acadéR mica mexicana y en la mía propia, ese torbellino intelectual que era Juan Carlos Garavaglia, gran historiador argentino y latinoamericano, fallecido en enero de 2017. El arribo de este apasionado colonialista a tierras mexicanas se debió a la generosidad de la acogida de la Universidad Autónoma Metropolitana (UAM) en la Ciudad de México, que en esos años contrataba a muchos profesores de diversas latitudes para impulsar sus nuevos departamentos de humanidades, ciencias sociales y ciencias naturales. La razón de esta generosidad se vinculaba directamente con la coyuntura económica, pues era el momento de auge del petróleo mexicano y la consiguiente abundancia fiscal que pudo canalizarse en una pequeña pero importante parte a las universidades públicas.

Fue después del derrocamiento de Salvador Allende, en septiembre de 1973, que las universidades mexicanas comenzaron a acoger a académicos exiliados de Sudamérica, en primer lugar, de Chile, y luego de cada golpe militar de los diversos países de la región: llegaron en número diverso de Bolivia, Guatemala, Haití, 
Brasil, Argentina y Uruguay, y pronto destacaron en sus respectivos campos de investigación y docencia. En la UAM-Iztapalapa, a donde llegó Juan Carlos Garavaglia, se incorporaron muchos profesores sudamericanos en todas las disciplinas, sobre todo en ciencias sociales. Algo parecido ocurrió en facultades de la Universidad Nacional Autónoma de México, en El Colegio de México, en la Universidad Autónoma de Puebla, y en diversos centros académicos de Veracruz y Nuevo León, entre otros estados.

Juan Carlos laboró cinco años con increíble energía y gran entusiasmo en el campus de la UAM en Iztapalapa, ubicado en la parte oriental de la gran urbe mexicana, en medio de un extenso barrio obrero. La carrera de historia formaba parte del Departamento de Filosofía. Además de la licenciatura en historia, que ya tenía numerosos alumnos, se había iniciado una maestría, la cual mucho debió a la conducción de Hira de Gortari, a la sazón jefe del Departamento de Filosofía (que incluía historia, literatura y filosofía). Nuestro "jefe" era un joven historiador muy cosmopolita, quien de manera muy diplomática y eficaz promovió la incorporación de un elenco de colegas de muy diversas tierras. La llegada de Garavaglia, sin duda, representó una chispa esencial para incentivar y motivar trabajos de historia económica y social latinoamericanos, pero hay que añadir que esto también se logró por las aportaciones del estimulante y diverso grupo de académicos que se había reunido en Iztapalapa. Sólo mencionaré algunos de mis colegas de entonces, que celebraron infinidad de seminarios y discusiones con Juan Carlos: entre ellos se contaban Juan Oddone, gran historiador uruguayo; Guy Pierre, haitiano; Jan Patula, polaco; Geralda Días, brasileña; Carmen Ramos y Norma Zubirán, mexicanas, así como Hira de Gortari, especialista en historia urbana, recién doctorado de la Universidad de París, a los que se sumaban otros colegas del área de historia, algunos de los cuales también habían estudiado en Francia.

En mi calidad de flamante y joven coordinador de la maestría en historia, me tocó trabajar muy estrechamente con Juan 
Carlos, quien - con su proverbial entusiasmo, inteligencia y alegría - fue alma de muchos proyectos de investigación y grupos de trabajos que dirigimos conjuntamente. Su extraordinaria dedicación a los alumnos y a estimular ideas y metodología novedosas se manifestó particularmente en los seminarios de tesis, los cuales fueron semillero de trabajos innovadores y claves en la formación de decenas de alumnos de muchas regiones de México, quienes hoy son profesores investigadores en diversas universidades y centros de investigación.

Garavaglia traía ya un equipaje intelectual formidable, habiendo adquirido una excelente formación por su empeño profesional y su trabajo con historiadores muy destacados en Argentina, Francia e Italia, lo cual contribuyó a que, al escucharlo como profesor e investigador, uno sintiera siempre la llegada de aires nuevos y la posibilidad de tejer vínculos con redes de académicos a escala internacional. Traía en esos momentos debajo del brazo un gran trabajo, que había sido su tesis doctoral, sobre la historia de la yerba mate en el Paraguay colonial, y que pudo publicar en México bajo el título de Mercado interno y economía colonial (1983)..$^{1}$ Ello fue posible gracias al vínculo con la oficina mexicana de la editorial Grijalbo, entonces dirigida por el inquieto Rogelio Carvajal. Dicho sea de paso, en el prólogo de este libro se delinean aspectos claves de la biografía intelectual de Juan Carlos, que vale la pena tener en cuenta en todo esfuerzo por recuperar su legado. El trabajo en cuestión era producto de una tesis doctoral realizada entre 1976 y 1979 en l'Ecole des Hautes Etudes en Sciences Sociales (EHss) de París, donde contó con la dirección del gran historiador Ruggero Romano. El libro es un magnífico estudio, muy meticuloso, sobre la reconstrucción del comercio y de la agricultura en la zona del Paraguay

${ }^{1}$ Juan Carlos Garavaglia, Mercado interno y economía colonial. Tres siglos de historia de la yerba mate, México, Grijalbo, 1983, y una $2^{\mathrm{a}}$ edición, en la colección de Prohistoria, Rosario, Argentina, 2008. 
en la época colonial; vale decir, en una de las regiones menos estudiada de la historia de la América española. En sus páginas se observa la huella pronunciada de los innovadores trabajos de Carlos Sempat Assadourian sobre el mercado interno colonial, pero también se nota la influencia de los debates inspirados por la colección editorial de Pasado y Presente, dirigida por el enérgico y polifacético intelectual José Aricó, desde la ciudad de Córdoba, Argentina, a partir de los años sesenta. ${ }^{2}$ Luego este proyecto de publicación de muy diversos clásicos del marxismo (de todos los colores y matices) tomaría nuevos impulsos por la asociación con la novel y efímera editorial Signos de Buenos Aires (fundada por Enrique Tandeter y el propio Garavaglia en 1973), pero sobre todo por su alianza con la editorial Siglo Veintiuno en la ciudad porteña durante los años de 1970, para pasar luego a editarse en México, ya que Aricó se exilió aquí tras el golpe militar de marzo de 1976 en Argentina.

Dentro de la vasta producción de los Cuadernos de Pasado y Presente (unos 98 a lo largo de más de 20 años y con ventas totales de cerca de un millón de ejemplares), se encontraban pocos textos propiamente de historia. Quizá el más original fue el número 40, preparado por Juan Carlos Garavaglia en 1972, donde analizaba la problemática de los diferentes modos de producción en la América colonial a partir de una colección de ensayos que pronto tuvieron amplia difusión en todo el hemisferio. Este cuaderno, titulado precisamente "Modos de producción en América Latina”, es una compilación con ensayos brillantes de varios intelectuales e historiadores marxistas latinoamericanos. En el primero, Ernesto Laclau revisa los debates sobre feudalismo y capitalismo en la región; le sigue el trabajo de Carlos Sempat Assadourian que vincula el estudio

2 José ArIcó, Entrevistas 1974-1991, presentación y edición de Horacio Crespo, Ediciones del Centro de Estudios Avanzados, Universidad Nacional de Córdoba, 1999. 
histórico de los modos de producción, capitalismo y desarrollo; por su parte, Ciro Cardoso analiza la obra de Severo Martínez Peláez y añade dos ensayos sobre modos de producción colonial y esclavista, al tiempo que Horacio Ciafardini aporta sus reflexiones críticas sobre el "capitalismo comercial”.

La contribución de Garavaglia a ese volumen se centró en proponer un estudio de caso de la economía y sociedad coloniales de Paraguay como un "modo de producción subsidiario". Este ensayo sugiere que Juan Carlos había iniciado sus primeras investigaciones históricas en el Paraguay colonial y comenzaba a plasmar algunas ideas centrales que servirían de eje para su futura tesis doctoral y, en realidad, para una buena parte de sus investigaciones posteriores. A todas luces, arrancó prestando una atención particular al papel del capital comercial en las economías coloniales, pero pronto se interesó aún más por la exploración de las bases materiales de la producción en las sociedades rurales en los siglos xviI y, especialmente, del siglo xviII. Como nos recuerda su gran amigo y colega, Raúl Fradkin, "Retrospectivamente Juan aclaró que empezó indagando el comercio porque las cuestiones relacionadas con la producción me parecían algo inaccesibles todavía” aunque "lo que realmente me interesaban eran los procesos productivos y tardé bastante en poder entrar en esas aguas". ${ }^{3}$

De acuerdo con el muy perceptivo ensayo de Fradkin, "Si pegamos un salto en el tiempo algo podrá advertirse de inmediato: su primer gran libro, Mercado interno y economía colonial sin duda se nutrió de su enriquecedora experiencia académica parisina; sin embargo, resulta evidente que había comenzado

\footnotetext{
${ }^{3}$ Fradkin cita el texto autobiográfico de Juan Carlos Garavaglia, Una juventud en los años sesenta, Buenos Aires, Prometeo libros, 2015, 208 pp., p. 144: véase Raúl FrADKIN, "Indicios y conjeturas: la formación de un historiador original”, en Prohistoria, 28 (dic. 2017), p. 264 http://www.scielo.org.ar/scielo. php?script=sci_issuetoc\&pid=1851-950420170002\&lng=es\&nrm=iso
} 
a imaginarlo, a pensarlo y a delinearlo mucho ante". ${ }^{4}$ Es decir, antes de partir a París en 1976 a hacer su tesis doctoral en la EHss, Juan Carlos ya estaba en vías de convertirse en uno de los más profundos y sistemáticos investigadores de las complejas estructuras demográficas, sociales, comerciales y agrícolas de las sociedades del antiguo régimen colonial en la América colonial, partiendo en muchos casos de regiones que podrían considerarse periféricas del imperio español, pero que revelaban algunas de sus rasgos más profundos y característicos.

Estos estudios previos sobre la zona guaraní-misionera y el conjunto del Paraguay colonial, a los que Garavaglia afirmó que había dedicado casi 12 años de investigaciones, fueron esenciales para desarrollar su nueva etapa profesional en México. ${ }^{5}$ En particular lo fueron en su afán por desentrañar los complejos secretos de la circulación y producción en las economías coloniales hispanoamericanas. Ello le facilitó enormemente el poder zambullirse en la historia mexicana del siglo xviII, atraído por la increíble riqueza de las fuentes que descubrió para el periodo borbónico.

Recuerdo el entusiasmo con el que Juan Carlos recibió la noticia hacia 1980 - tras el traslado del Archivo General de la Nación a Lecumberri- de la posibilidad de organizar el fondo de "alcabalas", merced a la iniciativa de Alejandra Moreno Toscano, la magnífica directora de ese archivo. Una vez identificadas unas quinientas cajas de documentación del ramo, Garavaglia se abalanzó sobre las series más completas que pudieron localizarse, con auxilio de algunos becarios. De allí también que pudo poner en marcha un ambicioso proyecto de investigación que desarrolló de la mano de su entrañable amigo, Juan Carlos Grosso, quien viajaba de Puebla por autobús a la Terminal de

${ }^{4}$ Fradkin, "Indicios y conjeturas", p. 274.

${ }^{5}$ Véase el prólogo de Juan Carlos Garavaglia en Mercado interno y economía colonial, p. 15. 
Autobuses de Oriente, para luego encontrarse con Garavaglia en el gran archivo, muy cerca de allí. Fueron tiempos emocionantes para ambos ya que hicieron notables descubrimientos sobre la riqueza y diversidad del comercio en el México virreinal, tanto de "productos de la tierra" como de los bienes importados, los "productos de Castilla". Sus publicaciones fueron legión y atrajeron la atención de numerosos alumnos y luego de profesores que siguieron trabajando estas vetas documentales que han demostrado ser enormemente fértiles. ${ }^{6}$

En mi humilde opinión, toda la obra conjunta de Garavaglia y Grosso sobre las alcabalas debiera digitalizarse, ya que son trabajos de relativamente difícil localización; además, incluyen series que si fueran volcadas en formato Excel serían de gran utilidad para nuevas generaciones.

Juan Carlos fue pionero en el esfuerzo por utilizar tempranamente los métodos de programación en cómputo con el fin de procesar gran cantidad de series. Esto me consta, ya que Garavaglia me animó a seguir con él un curso del lenguaje de "Basic", que nos impartió el ingeniero director de cómputo de la UAM-I durante más de medio año. Evidentemente, se estaba entonces en los albores de la aplicación de la computación a las ciencias sociales, pero con la ayuda de estas herramientas Garavaglia y Grosso procesaron mucha información muy detallada de los registros coloniales.

Para lograr una visión de conjunto de estas investigaciones, pueden recomendarse, en primera instancia, los estudios reunidos por Garavaglia y Grosso en el libro La región de Puebla y la economía novohispana: las alcabalas en la Nueva España,

\footnotetext{
${ }^{6}$ Se han hecho varios homenajes a la persona y obra de Juan Carlos Garavaglia que revelan su notable impacto: en primer lugar, la página web alojada en la Universidad de Tandil: http://www.unicen.edu.ar/iehs/homenaje/juancarlosgaravaglia.html. En segundo lugar, el excelente número monográfico de la revista Prohistoria, 28 (dic. 2017), p. 264: http://www.scielo.org.ar/scielo. php?script=sci_issuetoc\&pid=1851-950420170002\&lng=es\&nrm=iso
} 
1776-1821..$^{7}$ Esta obra abre con la introducción al volumen que ambos habían publicado en 1988, Las alcabalas novobispanas (1776-1821), editado por el Archivo General de la Nación de México. En este primer libro conjunto, incluyeron una colección de documentos sobre las alcabalas, una lista de las receptorías (con sus subreceptorías y pueblos dependientes) y la serie completa de la recaudación de aquellas durante el periodo 1777 1809. Explicaron en detalle la figura fiscal de la "alcabala" - una de las más antiguas de la España medieval, luego traspuesta a la América española-, la cual habría de convertirse en una de las más importantes de la hacienda colonial.

Todo instrumento fiscal tiene muchos vericuetos que pueden resultar algo complejos o confusos, pero los autores explicaron con espíritu muy didáctico quiénes tenían que pagar las alcabalas y cómo se cobraban, en tanto existían diversos tipos de este impuesto que afectaban a diferentes clases de contribuyentes, desde los más pobres a los más ricos. Explicaron con claridad los diferentes registros, incluyendo los libros reales de alcabalas, que contabilizaban sobre todo las operaciones superiores en valor a diez pesos, y los libros de viento, que registraban las transacciones menores de diez pesos, y que son una fuente en especial valiosa para conocer las características de las operaciones mercantiles en los tianguis o mercados locales. Aclararon también el funcionamiento de la categoría más difusa de las alcabalas, conocidas como iguales que "constituían un impuesto concertado, cuyo monto era fijado de común acuerdo entre el recaudador fiscal y el contribuyente, basado en un cálculo aproximado del valor que podría llegar a alcanzar las operaciones mercantiles o artesanales gravables durante un año".

7 Juan Carlos Garavaglia y Juan Carlos Grosso, La región de Puebla y la economía novohispana: las alcabalas en la Nueva España, 1776-1821, México, Instituto de Investigaciones Dr. José María Luis Mora, 1996. 
En la siguiente sección de su estudio, Garavaglia y Grosso entraron en el tema más complejo, que consistía en explorar y determinar qué expresaban las miles de series de alcabalas que existen para toda la Nueva España (y, dicho sea de paso, para el resto de la América española). Las mejores series son las que guardan los archivos entre los años de 1750 y 1810, cuando la renta dejó de ser arrendada al Consulado de Comerciantes de la Ciudad de México, como nos ha demostrado la historiadora Guillermina del Valle en múltiples y detallados trabajos. Ahora bien, lo que nos dicen muy precisamente las alcabalas, es cuánto recaudaban los reales funcionarios en la cobranza del impuesto sobre las mercancías introducidas en determinados mercados, urbanos o rurales. A su vez, los registros nos proporcionan una idea bastante precisa de los tipos de mercancías que se comercializaban, fuesen productos de la tierra (principales alimentos, ganado, pulques y telas) o productos de Castilla (importados), y en algunos bienes importados desde Asia y transportados por la nao de Manila. En este sentido, ofrecen una amplia radiografía de las transacciones mercantiles y de los volúmenes de recaudación sobre la misma. Sin embargo, no nos dicen todo, pues había importantes grupos que no pagaban alcabala, al menos habitualmente, incluyendo los indígenas de las repúblicas de indios y los miembros de la Iglesia. Al respecto, Garavaglia pasó largas horas tratando de descifrar la importancia y peso del comercio realizado por los indígenas en la zona de Tepeaca, donde encontró registros para principios del decenio de 1790 con información incluida excepcionalmente en los registros alcabalatorios. Y, además, planteó numerosos interrogantes que son materia fértil para futuros investigadores.

En efecto, sigue vigente la discusión sobre el verdadero significado de las alcabalas como espejo fiel de la evolución de la actividad mercantil en la Nueva España, ya que existe un conjunto de problemas teóricos y metodológicos que tratan la dificultad de establecer estas correspondencias. La economista 
e historiadora Mónica Gómez planteó este problema con agu$\mathrm{da}$ inteligencia en un ensayo revisionista en el que cuestionaba varios de los presupuestos que había adelantado Herbert Klein en sus trabajos clásicos sobre la fiscalidad en el México borbónico. ${ }^{8}$ En pocas palabras, el debate sigue abierto y pienso que a Garavaglia le hubiera encantado saberlo.

El segundo de los estudios del libro contiene un largo ensayo sobre las regiones de la Nueva España, publicado originalmente con el título de "Le regioni della Nueva España nel periodo borbonico: un'analisi cuantitativa, 1778-1809", en la Rivista Storica Italiana. ${ }^{9}$ En dicho trabajo se comparan los montos globales de recaudación de alcabalas en las principales administraciones alcabalatorias del virreinato, y se evalúan sus tendencias, en general de crecimiento por regiones, si bien en algunas zonas como Guanajuato, Puebla y Oaxaca hubo un notorio estancamiento entre 1778 y 1809. A su vez, se proponen algunas comparaciones con las tendencias demográficas, aunque la información de base poblacional no es por demás completa ni seriada. En todo caso, la propuesta era realmente interesante en tanto que sugiere algunas posibilidades para "regionalizar" los análisis de la economía y la población de la Nueva España a lo largo de casi medio siglo.

Un tercer capítulo, titulado "De Veracruz a Durango: un análisis regional en la Nueva España borbónica”, da continuidad a los planteamientos previamente citados, pero centrándose en algunas de las zonas más dinámicas de la época tardía borbónica, lo cual se vinculaba con la instrumentación de las nuevas

\footnotetext{
${ }^{8}$ Mónica Gómez, "El debate sobre el ingreso fiscal y la actividad económica. El caso de la Nueva España en el siglo xviII," en Carlos Marichal y Daniela MARINo (eds.), De colonia a nación: impuestos y política en México, 1750-1860, México, El Colegio de México, 2001, pp. 115-130.

9 Juan Carlos Garavaglia, "Le regioni della Nueva España nel periodo borbonico: un'analisi cuantitativa, 1778-1809”, en Rivista Storica Italiana, XCIX, facs. III (1987).
} 
medidas de "libre comercio" establecidas dentro del imperio español. ${ }^{10}$ Finalmente, en el cuarto y último capítulo del volumen, los mismos autores proporcionan una serie de estudios sobre la evolución de las alcabalas desde fines del siglo xvir hasta principios del siglo xIx. En su estudio se perfilan algunas de las grandes tendencias de expansión y contracción de las economías regionales de Puebla y Tlaxcala en este siglo y medio, las cuales sufrieron algunos momentos de fuerte crisis seguidos de ligeras recuperaciones.

En un segundo libro, Garavaglia y Grosso ahondaron en la temática de la economía y sociedad coloniales desde un enfoque mucho más delimitado. Producto de este esfuerzo es el conjunto de ensayos titulado Puebla desde una perspectiva microhistórica. La villa de Tepeaca y su entorno agrario: población, producción e intercambio (1740-1870). ${ }^{11}$ En este volumen reunieron una serie de estudios que incluían detallados análisis demográficos, trabajos sobre la estructura ocupacional, la reconstrucción de series alcabalatorios y diezmatorios, así como notables estudios de diferentes tipos de haciendas, en su mayoría trigueras y maiceras. Una simple relación de los archivos consultados revela la vastedad del proyecto de investigación: incluía archivos del Ayuntamiento de Puebla, de la Catedral de la misma ciudad, Archivo General de Indias, Archivo General de la Nación de México, archivos de notarías y judiciales de Puebla, así como los archivos municipales de Tepeaca. La profundidad de la reconstrucción del comercio, la agricultura, los telares y las haciendas,

${ }^{10}$ Juan Carlos Garavaglia y Juan Carlos Grosso, "De Veracruz a Durango: un análisis regional en la Nueva España borbónica”, en Siglo XIX. Revista de Historia, II: 4 (1987), pp. 9-52.

${ }^{11}$ Juan Carlos Garavaglia y Juan Carlos Grosso, Puebla desde una perspectiva microhistórica. La villa de Tepeaca y su entorno agrario: población, producción e intercambio (1740-1870), Claves Latinoamericanas, Universidad Autónoma de Puebla, México, Universidad Nacional del Centro (Tandil, Argentina), 1994. 
por medio de un gran cúmulo de testamentos, documentos eclesiásticos y civiles, revela una sociedad por demás compleja $\mathrm{y}$ en proceso de cambio tanto económico como social.

La influencia de este tipo de trabajos en varias generaciones de historiadores de México fue notable, especialmente entre los jóvenes investigadores de varias regiones que comenzaban a trabajar en los años 1980 y 1990, y que siguen siendo de los más productivos historiadores económicos de México: Francisco Cervantes Bello, Jorge Silva Riquer, Guillermina del Valle Pavón, Matilde Souto, Antonio Ibarra, Yovana Celaya Nández, Ana Lidia García Peña, Enriqueta Quiroz, Ernest Sánchez Santiró, José Antonio Serrano, Luis Jáuregui, entre muchos otros. Revisar sus trabajos permite constatar la influencia de los trabajos pioneros de Garavaglia y Grosso como importantes estímulos a la abundantísima serie de trabajos sobre historia económica y social colonial que se han publicado en México a lo largo de los últimos 40 años. En mi propio caso, debo confesar que si bien en un inicio no estaba tan involucrado en la historia económica colonial, fueron los dos Juan Carlos y esta nueva generación de estudiosos quienes habrían de seducirme, dejando una fortísima impronta en algunas de los ejes de mi propia investigación, sobre todo desde el decenio de 1990 en adelante.

La estancia en México de los dos Juan Carlos no fue larga, pero sí muy productiva. Después del fin de la dictadura en Argentina (a fines de 1983), tanto Garavaglia como Grosso decidieron regresar al Río de la Plata, razón por la cual a partir de 1985 se incorporaron al flamante departamento de historia, en la Universidad de Tandil, en el centro de la provincia de Buenos Aires. Allí impulsaron nuevos grupos de trabajo, revistas, libros y también formaron muchos alumnos (algunos de los cuales luego viajarían a México a estudiar en El Colegio de México), la mayor parte de ellos hoy profesores en diversos centros académicos del continente. Posteriormente, y de nuevo, el siempre inquieto Garavaglia se trasladó a París incorporándose 
a la Escuela de Altos Estudios en Ciencias Sociales (EHEss), donde destacó como profesor e investigador, y publicó infinidad de obras de historia latinoamericana en español y en francés.

En cierto sentido, su regreso a París era como un regreso a una casa de estudios que ya era muy suya y que permitió que atrajera a jóvenes latinoamericanos a hacer posgrados allí. En esa época de los años de 1990 no sólo impulsó multitud de seminarios sobre historia latinoamericana, sino que también convocó a alumnos y profesores de muchos países a participar en siempre efervescentes debates intelectuales. A su vez, al mantener sus vínculos con la comunidad de historiadores en Argentina, especialmente en Buenos Aires y Tandil, contribuyó a renovar y ampliar de manera notable la visión y comprensión de la historia agraria del Río de la Plata en el siglo xviII y principios del siglo xIX, al utilizar en muchos casos herramientas de trabajo y de archivo que había desarrollado en México.

Desde mi particular punto de vista, concluyo que a lo largo de las distintas etapas de su vida académica, Garavaglia clara e intuitivamente eligió concentrar su atención en los estudios de las sociedades rurales de fines del siglo xvir y a lo largo del siglo XVIII; concretamente encontramos muchísimos paralelos entre sus trabajos sobre los campesinos y los mercados de antiguo régimen colonial en Paraguay, en México (en particular la región de Tepeaca), y en el litoral del Río de la Plata. Como resultado, todos sus estudios hacen necesario corregir la opinión de que sólo los comerciantes, con una práctica y perspectiva mercantil ("capitalista"), habrían de construir los eslabones de economías regionales interconectadas. Sin duda, las oligarquías de mercaderes eran intermediarios clave, pero en realidad fueron los campesinos, los artesanos y los esclavos (que trabajaban tanto en las villas y ciudades como en el campo) los que habrían de proporcionar los fundamentos materiales tanto de la producción local como de una serie de elementos y mercancías claves en una época de temprana globalización. Raúl Fradkin lo ha sintetizado 
mejor que nadie al señalar cuáles eran algunos de los ejes clave que guiaron las múltiples investigaciones de Garavaglia. En un reciente y brillante ensayo se interroga y responde:

Pero, una pregunta resulta insoslayable: ¿qué era lo que unía el estudio del comercio, la yerba mate, el trigo y el maíz, a Yapeyú, Tepeaca y Areco, los ponchos, los ganados, los mercados, las relaciones de producción, las tecnologías, la agrimensura, los ecosistemas, la fiscalidad, la demografía, la formación de los estados y las naciones, los rituales, la justicia, los pueblos? ¿la guerra o la política? ¿Es posible reconocer un "gran tema” que los hilvanara? Cada vez que se lo pregunté, solo me respondía: "una cosa te lleva a la otra”. Pero desde mi punto de vista sí tuvo un "gran tema": la historia de los campesinos latinoamericanos y con ellos, las historias de los hombres y las mujeres del común. ${ }^{12}$

Más allá de sus investigaciones tan diversas que - como descubrimos, estaban estrechamente entrelazadas conceptual y metodológicamente - no hay duda que queda en la memoria la calidad humana de este historiador, sonriente, polémico, irónico, audaz y ocurrente, el cual se expresó en un gran afán por contribuir a la formación de alumnos y enriquecer el diálogo permanente con colegas. Quizá una de las facetas más sorprendentes de Juan Carlos Garavaglia fue su capacidad de impulsar grupos de trabajos, incluidos muchos profesores y alumnos, por ejemplo, en México, en los tempranos años ochenta, pero más recientemente - desde los años noventa - en varios países a la vez: en Francia, en España - en los famosos cursos de verano en Huelva que codirigía con Juan Marchena - y en Argentina con nutridos círculos y redes de trabajo. Ya en tiempos más recientes, Juan Carlos se había trasladado a la Universidad Pompeu Fabra en Barcelona, y tuvo la fortuna de adquirir una casa de

12 Fradkin, “Indicios y conjeturas", p. 259. 
campo donde residía en el sur de Francia. Me imagino que allí habrá escrito su último libro autobiográfico. Yo tenía planeado hacer un peregrinaje hace un par de años a visitarlo para poder disfrutar de su conversación siempre amena, su estupendo sentido de humor y su vitalidad y curiosidad incesantes. $\mathrm{Me}$ he quedado con las ganas y me entristece profundamente, pero aprovecho esta nota para mandarle un fuerte abrazo a este gran amigo que espero esté caminando por los jardines de los Campos Elíseos, discutiendo sobre mil y un temas, como siempre, con todos sus amigos. Se nos fue un gran historiador y colega que extrañamos aquí en México y a cuya memoria dedicamos estas páginas. 